\title{
Caesarean Section Characteristics Based on Robson Classification at Sanglah Hospital
}

\author{
Sugianto, A. A. N. Jaya Kusuma, Tjok G. A. Suwardewa, I. B. Putra Adnyana, I. G. N. Harry \\ Wijaya Surya
}

\section{ABSTRACT}

Background: Improving maternal and child health can be achieved through programs aimed at reducing maternal mortality rate (MMR) and infant mortality rate (IMR). Apart from going through a normal delivery, labor can also be done by abdominal surgery/ cesarean section (CS). A safe and timely Cesarean Section (CS) remains a major challenge in countries with high MMR, which poses new challenges to these countries in being able to minimize CS without clinical indication. This study aims to determine the rates and characteristics of patients underwent $C S$, indications of $C S$, as well as the rate of CS based on Robson's classification system.

Methods: A retrospective descriptive study of labor and delivery cases in the Sanglah General Hospital Denpasar was conducted from the period of $1^{\text {st }}$ January 2018 - $31^{\text {st }}$ December 2018.

Results: From 1121 deliveries in 2018, the rates of CS in that period were $34.3 \%$. As many as $28.1 \%$ were the age of $25-29$ years. The $31.9 \%$ subjects were primigravida, with the gestational age was term around $66 \%$. The majority of samples around $\mathbf{7 3 . 2 \%}$ did not have a history of previous CS. Using Robson criteria, we found that the biggest contribution for CS rate was from group $10(23.38 \%)$, then group $5(15.84 \%)$ and group $2(13.51 \%)$.

Conclusion: Around 385 cases of labor with CS were obtained from a total of 1121 deliveries in $2018(34.3 \%)$. The highest rate was found in the age group of 25-29 years, mothers with first pregnancy (primigravida), most of the gestational age was term, majority did not have a history of previous CS and the highest contribution of CS rate was from Robson group $10(23.38 \%)$.

Keywords: Caesarean Section, characteristics, Robson classification.

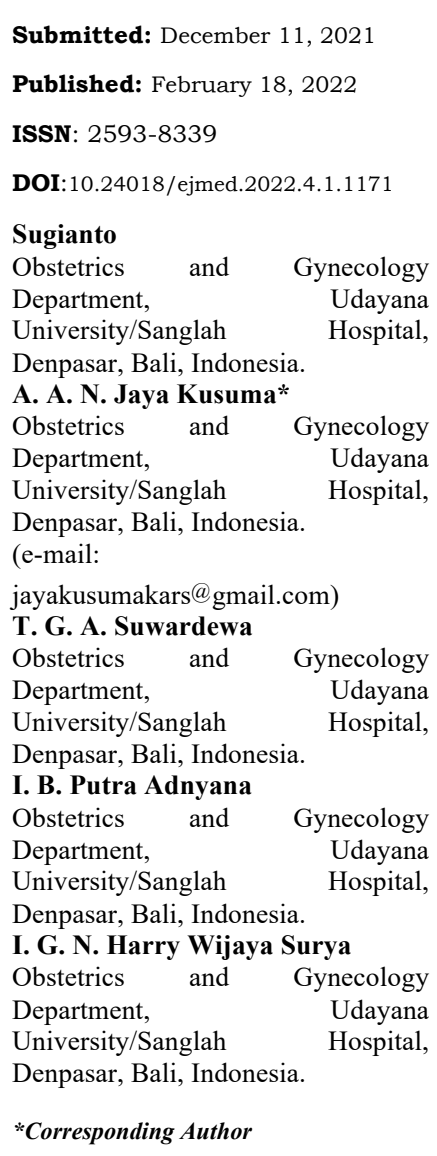

\section{INTRODUCTION}

The development of the health sector basically aims to accelerate the level of welfare. One of the manifestations of these efforts is improving maternal and child health through programs aimed at reducing maternal mortality rate (MMR) and infant mortality rate (IMR). Ministry of Health policy in the last decade emphasizes that an effort to reduce MMR can be done by encouraging an assisted delivery by trained health workers namely obstetrics and gynecology specialists, general practitioners, and midwives, and strived to be done in health care facilities. Therefore, starting in 2015, the emphasis on safe delivery is labor assisted by health workers in health care facilities [1].

Apart from normal delivery, labor can also be done by way of abdominal surgery/ cesarean section (CS). CS operations which is performed correctly and following accurate medical indications are life-saving procedures. That's why a safe and timely CS remains a major challenge in countries with high MMR, which poses new challenges to these countries in being able to minimize CS operations without clinical indication [2].
According to the latest estimation, the average number of CS worldwide is $19.1 \%$ and increased annually [3]. In Indonesia, based on the results of the 2013 Riset Kesehatan Dasar (Riskesdas), the number of births by CS in the period 2010-2013 was $9.8 \%$ for the national average, and $17.3 \%$ for the Bali province which was the third highest CS number in Indonesia [4].

Many factors affect the increasing number of CS. These factors include improved techniques and procedures for surgery and anesthesia, improved economic status, decreased risk and complications after surgery, changes in the health care system, and increased patient awareness to determine their own way of delivery [5]. Some of patient's reason that underlie the increase in the number of CS are not resistant to labor pain and worriness regarding female organ changes after vaginal delivery, they consider CS more comfortable and safer than vaginal delivery, and some wants to give birth on a good or beautiful date. While some reasons from health workers include being easier in time allocation, and to avoid complications or medical litigation due to complications arising from the delivery process [3]. 
On the other side, studies conducted by WHO show that CS measures will increase maternal morbidity and mortality $(2 \%)$, the need for blood transfusion $(0.4 \%)$, the rate of hysterectomies $(0.1 \%)$, length of stay in hospital $(0,7 \%)$, and the rate of care in intensive care units until maternal death $(0.2 \%)$ [5]. In infants, the risk that can occur is lacerations in infants of $1-2 \%$ in labor with CS, which is not found in vaginal delivery, while the risk of respiratory distress is found in $1-4 \%$ in labor with $\mathrm{CS}$, higher compared to vaginal delivery which is only $<1 \%$ [6]. Therefore, unnecessary CS need to be reduced in order to reduce maternal morbidity and mortality and reducing the amount of unnecessary health financing, we need a system that can be used to monitor and compare CS rate in health facilities from time to time, and also in other health facilities with different environments [7]. This shows that it is very necessary to have valid data about CS rates.

Generally, developed countries already have a national baseline data to monitor the number of CS to be able to see the classification and characteristics of CS in the country. Over the past decade there have been around 27 known CS classifications worldwide and divided into 4 major classifications namely Indication Based, Degree of Urgency Based, Woman Based, Other Types (based on indications, level of emergency, based on women, and other types) [8]. In 2014, the World Health Organization (WHO) recommended a classification system as a global standard for assessing and monitoring CS rate, as well as a standard comparing CS rate among other health facilities, as well as in different periods of time in the same health facilities The classification was introduced by Michael Robson who worked as a doctor in 2001, a system known as the "Robson Classification" system [9]-[11].

This study aims to determine the rates and characteristics of CS operations and risk factors associated with CS in Sanglah Hospital Denpasar during the period of $1^{\text {st }}$ January 2018 - $31^{\text {st }}$ December 2018 based on the Robson classification system.

\section{METHODS}

This is a retrospective descriptive study of labor and delivery cases in the Sanglah General Hospital, Denpasar. The study was conducted in the Department of Obstetrics and Gynecology, Sanglah Hospital, Denpasar. Data was collected from the weekly report records of the Department of Obstetrics and Gynecology of Sanglah Hospital in Denpasar for the period of $1^{\text {st }}$ January $2018-31^{\text {st }}$ December 2018 which was sourced from the obstetric emergency room birth register and the elective surgery scheduled from the obstetric outpatient clinic in the Sanglah Hospital Denpasar.

The study subject were patients who underwent CS surgery which were recorded in the weekly report of the Department of Obstetrics and Gynecology at Sanglah Hospital Denpasar. The scope of this study includes the characteristics of patients underwent CS, indications of CS surgery, as well as the rate of CS based on Robson's classification system.

Data from CS subjects obtained were then categorized to determine the characteristics of the study sample. Then the data is classified into groups - using the Robson classification system to identify the level and indication of CS in each group. All data is retrieved and entered into pre-structured performance. The data collected was then analyzed using simple statistical measures such as percentages and proportions and then a descriptive statistical analysis was performed.

\section{RESULTS}

Based on data from the weekly report records of the Department of Obstetrics and Gynecology, Sanglah General Hospital for the period of $1^{\text {st }}$ January $2018-31^{\text {st }}$ December 2018 which was sourced from the obstetric emergency room birth register and the elective surgery scheduled from the obstetric outpatient clinic of the Sanglah Hospital, 385 CS cases were obtained from a total of 1121 deliveries in 2018 . The rates of CS in that period were $34.3 \%$ (Fig. 1, Table I).

\begin{tabular}{|c|c|}
\hline Subject Characteristics & Value (n) \\
\hline \multicolumn{2}{|c|}{ Age (years) } \\
\hline$\leq 19$ & 10 \\
\hline $20-24$ & 82 \\
\hline $25-29$ & 108 \\
\hline $30-34$ & 84 \\
\hline$\geq 35$ & 101 \\
\hline \multicolumn{2}{|c|}{ Pregnancy Frequency } \\
\hline 1 & 123 \\
\hline 2 & 107 \\
\hline 3 & 100 \\
\hline 4 & 34 \\
\hline$\geq 5$ & 21 \\
\hline \multicolumn{2}{|c|}{ Pregnancy Age (weeks) } \\
\hline$<<28$ & 4 \\
\hline $28-36$ & 127 \\
\hline$\geq 37$ & 254 \\
\hline \multicolumn{2}{|c|}{ History of Caesarean Section } \\
\hline 0 & 282 \\
\hline 1 & 70 \\
\hline 2 & 28 \\
\hline$\geq 3$ & 5 \\
\hline
\end{tabular}

During 2017, out of 1093 cases of childbirth, 303 cases (27.7\%) of them were CS cases. Other data in 2016 revealed that out of a total of 1242 deliveries, 301 cases (24.2\%) were carried out with CS. In other words, the data shows that from 2016 to 2017 in Sanglah Hospital there was an increase in CS rates by $3.5 \%$, while from 2017 to 2018 an increase in CS rates was $6.6 \%$, almost doubled the previous period. From these data it is known that the CS rate is still higher than the results of the Riskesdas for the period 2010 - 2013, where the CS rate for that period was $9.8 \%$ for the national average, and by $17.3 \%$ for Bali province [4]. The CS rate is also higher than the ideal CS rate agreed by the International Health Care Community since 1985, which is between 10-15\% [9].
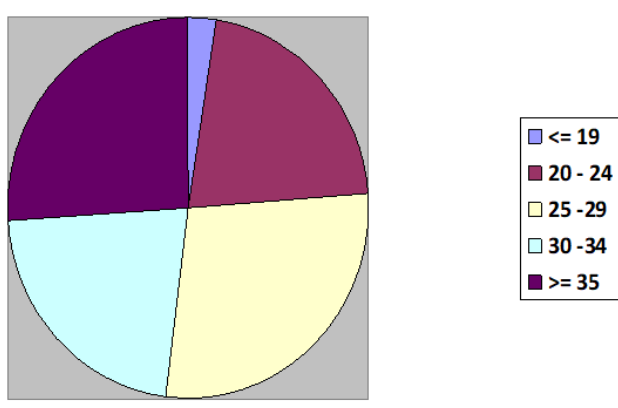

Fig. 1. Subject characteristic based on age. 
Fig. 1 shows that most of the CS subjects were the age group $25-29$ years with 108 subjects $(28.1 \%)$, followed by the age group $\geq 35$ years of 101 subjects $(26.2 \%)$, the age group $30-34$ years as many as 84 subjects $(21.8 \%)$, the age group of $20-24$ years were 82 subjects $(21.3 \%)$ and at least that was in the age group $\leq 19$ years as many as 10 subjects $(2.6 \%)$.

As many as $31.9 \%$ or 123 subjects undergoing CS in this study were mothers with first pregnancy (primigravida), and the remaining $262(68.1 \%)$ were multigravida. Among the 262 multigravida, as many as 107 people $(27.8 \%)$ of whom were mothers with second pregnancies, 100 people $(26 \%)$ were in third pregnancies, 34 people $(8.8 \%)$ with fourth pregnancies, 21 people $(5,5 \%)$ with a pregnancy more than five times (Fig. 2).
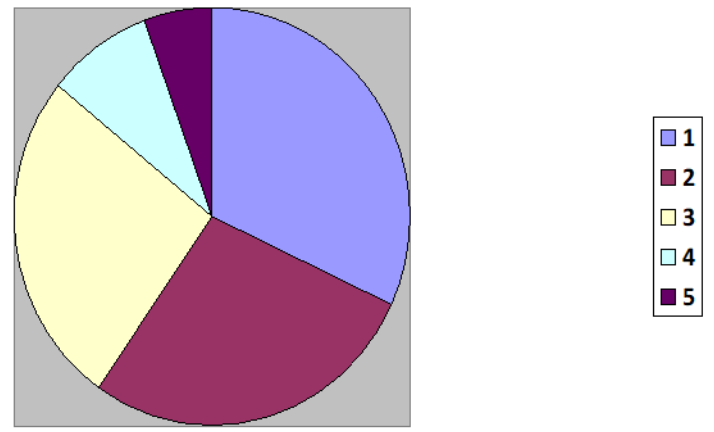

Fig. 2. Subject Characteristic based on pregnancy frequency.

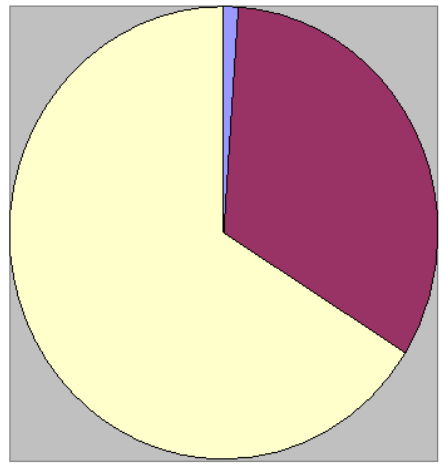

$\square<28$ weeks

$\square 28$ - 36 weeks

$\square>=36$ weeks

Fig. 3. Subject characteristic based on pregnancy age. cases were preterm pregnancies: 4 cases (1\%) with gestational age $<28$ weeks and 127 cases $(33 \%)$ with gestational age 28-36 weeks.

After analyzing the data based on the Robson system, data were classified into10 Robson groups. It was then entered in the columns (columns 1 - 7) of the Robson reporting reference table to see the CS rates in each group and their contribution against the whole CS rates as shown in Table II.

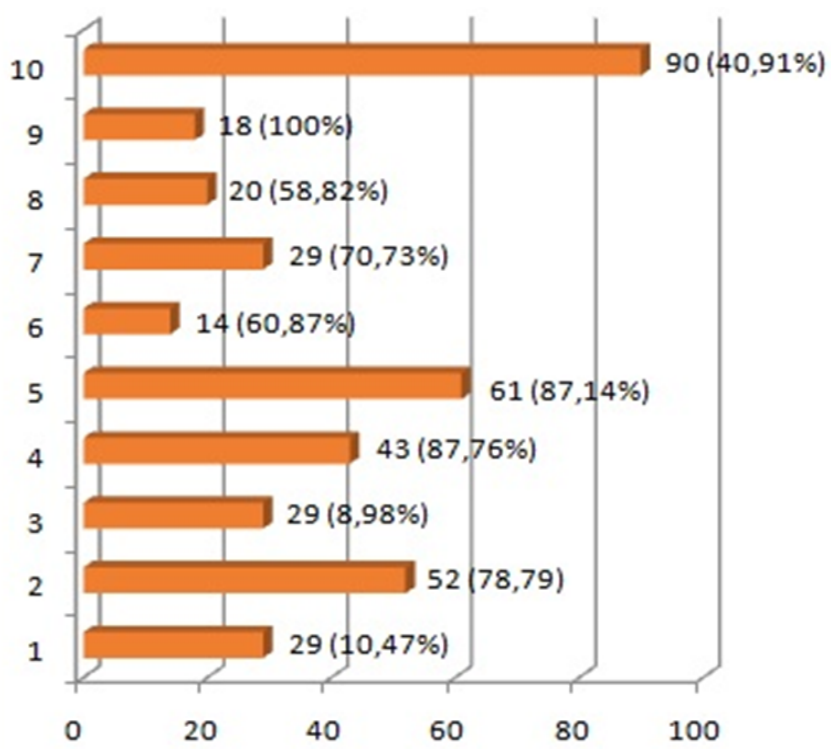

Fig. 4. Caesarean cection rates among Robson's group from $1^{\text {st }}$ January 2018-31 ${ }^{\text {st }}$ December 2018.

Data obtained showed that the largest rate of CS (Fig. 4) was obtained from group $10(40.91 \%)$ with a total of 90 cases, then group $5(87.14 \%)$ with a total of 61 cases and group 2 (78.79\%) as many as 52 cases, which have contributed to the number of CS of $34.3 \%$. The rate of CS was not much different from the rate of CS in the United States in the 2017 period which is $32 \%$. Both of these CS rates are higher than those recommended by WHO which was $15 \%$. Those datas illustrated that 1 in 3 patients who give birth undergo CS.

Fig. 3 shows that most of the gestational age of subjects was term, which was 254 cases $(66 \%)$. The remaining 131

\begin{tabular}{|c|c|c|c|c|c|c|}
\hline Column 1 & Column2 & Column 3 & Column 4 & Column 5 & Column 6 & Column 7 \\
\hline Group & $\begin{array}{l}\text { CS rates in group } \\
\text { (n) }\end{array}$ & $\begin{array}{c}\text { Number of } \\
\text { Woman in group } \\
\text { (n) }\end{array}$ & Group size (\%) & $\begin{array}{c}\text { CS rates in group } \\
(\%)\end{array}$ & $\begin{array}{c}\text { Absolute group } \\
\text { contribution to } \\
\text { overall CS rate } \\
(\%)\end{array}$ & $\begin{array}{c}\text { Relative group } \\
\text { contribution to } \\
\text { overall CS rate } \\
(\%)\end{array}$ \\
\hline 1 & 29 & 277 & 24,71 & 10,47 & 2,59 & 7,53 \\
\hline 2 & 52 & 66 & 5,89 & 78,79 & 4,64 & 13,51 \\
\hline 3 & 29 & 323 & 28,81 & 8,98 & 2,59 & 7,53 \\
\hline 4 & 43 & 49 & 4,37 & 87,76 & 3,84 & 11,17 \\
\hline 5 & 61 & 70 & 6,24 & 87,14 & 5,44 & 15,84 \\
\hline 6 & 14 & 23 & 2,05 & 60,87 & 1,25 & 3,64 \\
\hline 7 & 29 & 41 & 3,66 & 70,73 & 2,59 & 7,53 \\
\hline 8 & 20 & 34 & 3,03 & 58,82 & 1,78 & 5,19 \\
\hline 9 & 18 & 18 & 1,61 & 100 & 1,61 & 4,67 \\
\hline 10 & 90 & 220 & 19,63 & 40,91 & 8,03 & 23,38 \\
\hline
\end{tabular}




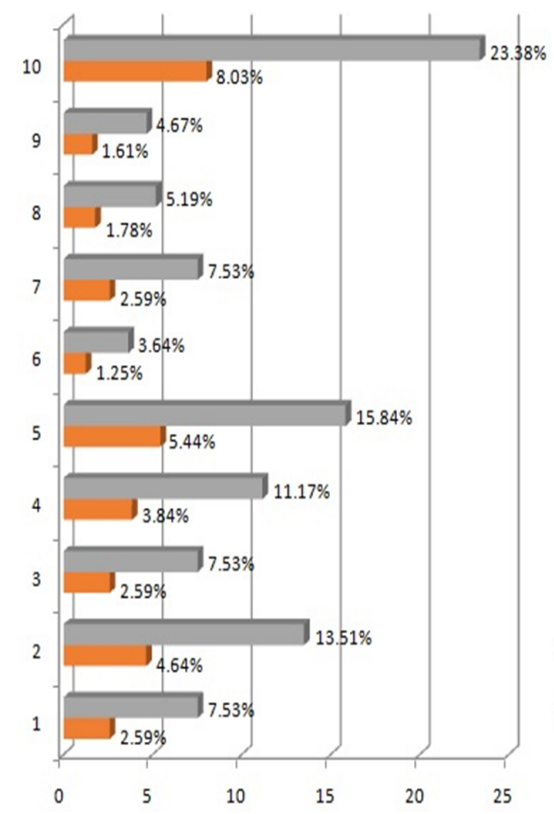

| Relative contribution group to CS (\%)

- Absolut contribution group to CS (\%)

Fig. 5. Each Robson Group Contribution to Caesarean Section Rates from 1st January 2018-31st December 2018.

Fig. 5 shows that the maximum contribution of the CS rate was the Robson group $10(23.38 \%)$ which was a group that covers all women with a single fetus, head presentation, gestational age $<37$ weeks, also including those with a history of CS. The group that experienced a trend of increasing CS rates and the second largest contribution to $\mathrm{CS}$ rates was group 5, contributing around 15.84\% which included multipara women with a history of CS, single fetus, head presentation and term gestational age. The third largest was group $2(13.51 \%)$ which included nullipara women with a single fetus, head presentation, term gestational age, with induction of labor or CS before labor onset. In Group 10 the high rate of CS may be due to the limited facilities and resources to care for premature babies (eg limited NICU, etc.) in regional and private hospitals in Bali, so there will be many cases with the threat of preterm birth that require intervention and special treatment will be referred to Sanglah Hospital which is the only tertiary hospital in Bali. In group 5, it was known that a previous history of CS has a greater role in increasing the likelihood of CS surgery, where patients such as this are usually often offered for scheduled CS procedures, but it also showed that these patients often refuse to do vaginal delivery trials even though it has been offered. Data show that of all women who have a previous history of CS, around $56 \%$ are indicated to undergo CS surgery, while around $44 \%$ are indicated to undergo vaginal delivery trials. Data showed that the rate of vaginal delivery trials continues to decline each year due to fears of the risk of uterine rupture. In group 2, it was known that the presence of labor induction beforehand was found to play a role in increasing the number of CS [12].

The rate of CS surgery in group 1 (nullipara women with a single fetus, head presentation, gestational age at term and in the spontaneous labor phase) was $10.47 \%$ and group 3 (multipara women without a history of CS, single fetus, head presentation, gestational age at term and in the spontaneous labor phase) was $8.98 \%$. It was lower when they came in spontaneous labor when compared to group 2 (nullipara women with a single fetus, head presentation, term gestational age, with induction of labor or CS before labor onset) of $78,79 \%$ and group 4 (multipara women without a history of CS, single fetus, head presentation, gestational age at term, with induction of labor or CS before onset of labor) of $87.76 \%$. Each labor in the two groups begins with labor induction, which was known that labor induction actually plays a role in increasing the rate of CS [12].

\section{DISCUSSION}

From this study it showed from a total of 385 cases of childbirth with CS, the highest rate was found in the age group of 25-29 years, while the second highest group at the age above 35 years. With study subjects undergoing CS, $31.95 \%$ were mothers with a first pregnancy (primigravida), and $68.05 \%$ were multigravida. While the gestational age of the subjects was mostly at term.

The high rates of CS might be due to Sanglah Hospital is the only tertiary hospital in the Province of Bali and is a referral center hospital for the Eastern Indonesia region, so that many of the labor cases handled were high-risk cases with complications that required special approches.

From this study, it can be seen that overall, the highest number of CS was found in the age group of 25-29 years, while the second highest group at the age 35 years and above. A study conducted over 18 years (1998 - 2015) in Denmark stated that there was a correlation between the increase in the number of CS with increasing age of pregnant women. In that study, CS rate of $21 \%$ was obtained for mothers over 35 years of age. Pregnancy at that age has been known to be closely related to abnormalities during pregnancy and complications during delivery period such as high blood pressure/preeclampsia, gestational diabetes mellitus, placenta previa, and miscarriage due to decreased function of uterine contractions, all of which can be associated risk factors and contribute on the increased risk and the reasons for CS [13].

Although the rate of CS among multigravida was higher than primigravida, but if we look closely, we can also conclude that the number of CS decreases proportionally with the increasing number of pregnancies (parity). This is in accordance with the study by Hanson, involving 34,063 research data taken in 2007 and 2013, from which the data showed the CS rates were getting lower with increasing parity [14].

From this study, it can be seen that the gestational age of the sample is mostly term. This result is similar with the study by Begum that involving 2549 deliveries with a CS rate of $35 \%$ where the highest CS rate was obtained at term gestational age ( $\geq 37$ weeks) of $89.14 \%$ and the remaining $1.33 \%$ at age Preterm pregnancy [15].

In this study, the group that experienced a trend of increasing CS rates and provided the largest contribution to CS rates were group 10, 5 and 2 . In a study conducted by Tanaka and Mahomed at Ispwich Hospital - Quensland Australia, it was found that the group that gave the biggest contribution to the rate of CS in the period January 2015 December 2015 was group 5 which was $10.9 \%$ (the number of CS in the group was as many as 287 cases out of 375 deliveries), while the second largest group that gave the maximum contribution was group 2, which is $2.9 \%$. This difference may be due to the limited facilities and resources 
for caring for premature babies (eg limited NICU space, etc.) in regional and private hospitals in the Bali region, so there will be many cases of preterm birth that require special intervention and treatment will be referred to Sanglah Hospital which is the only tertiary hospital in Bali. And it might be very different from the Ipswich - Australia region which has more evenly distributed NICU facilities in each region.

All three indications of CS found in this study were in accordance with 2 of the 4 main indications published by ACOG in 2014, where labor dystocia, non-reassuring fetal status, malpresentation and multiple pregnancy were the 4 main reasons for CS. Also, in accordance with 3 of the 4 indications presented by Cunningham that more than $85 \%$ of CS surgeries were performed for four main reasons, namely, a history of previous cesarean delivery, dystocia, fetal distress, or abnormal fetal presentation.

The high rates of CS were not directly proportional to the high quality of service and does not necessarily reduce the morbidity and mortality rates for mothers and infants. Many studies have found that higher rates of CS delivery do not necessarily increase maternal or fetal outcomes and can even cause problems due to CS itself. Various guidelines including those issued by WHO showed that the optimal CS level is around $15 \%$. Rates below 5\% imply that most women do not have access to surgical obstetric care, while higher than $15 \%$ may indicate excessive use of CS procedures for weak indications. CS surgery increases the duration of hospital stay, the need for blood transfusion and increases the risk of anesthetic complications such as thromboembolism and infection at the surgical site. As the number of CS surgeries increases, the risk of bladder injury and placenta adhesive also increases with serious maternal morbidity and even death [16].

Standardization and classification of CS deliveries was done for the first time in our obstetric department according to Robson's criteria which was an attempt to see which groups were clinically relevant as the highest contributor to cesarean delivery. As we observed in this study, the rate of CS in our hospital at Sanglah General Hospital in 2018 was 34.3\%, which was higher than what the WHO suggested was $15 \%$.

Vogel in his study tried to analyze the contribution of certain groups to $\mathrm{CS}$ rates through the Robson 10 group classification system. He performed two WHO multi-country surveys and concluded that the proportion of women with a history of previous CS operations had increased with increasing CS operations. The use of induction itself, CS operations before onset of labor and CS after induction in multipara also contributed to the increase in the group. This can be seen in this study where groups 2 and 4 have a higher level of CS compared to groups 1 and 3 [10].

Therefore it is necessary to limit the induction of labor. Cases that require labor induction must be based on evidence and facts about the condition of pregnancy which was believed to require such actions. ACOG in 2014 recommends a clinical guideline in induction for limiting the number CS deliveries. Induction of labor before $410 / 7$ weeks of gestation should be performed based on maternal and fetal medical indication. Induction beyond $410 / 7$ weeks of gestation and beyond should be performed to reduce the risk of cesarean delivery and the risk of perinatal morbidity and mortality.
Cervical ripening should be used when labor is induced in woman with an unfavorable cervix. If maternal and fetal status allow cesarean deliveries for failed induction of labor in latent phase can be avoided by allowing longer duration of latent phase (up to 24 hours or longer) and requiring that oxytocin be administered for at least $12-18$ hours after membrane rupture before deeming the induction a failure. Apart from that, efforts must be made to standardize the interpretation of reactive - non-reactive NSTs, intrapartum CTGs as categories 1 to 3 . A routine and periodic critical evaluation are needed to carefully select the existing CS indications. This will not only reduce the level of CS operations in nullipara but ultimately will also reduce CS operations in multipara with previous CS history operations [6].

The hospital where the study was conducted is a tertiary care center and Eastern Indonesia referral where a large number of high-risk cases have been referred. These could be the reason for such a high rate of CS because it increase the likelihood that labor ends with CS due to maternal and infant reasons. It is a positive thing if we can reduce the number of $\mathrm{CS}$ as ideal as possible. These efforts can be done by reducing the rate of CS in the primipara group and using the trial of vaginal delivery after the previous CS (VBAC) wisely. Appropriate patient selection and counseling in the antenatal period can increase the number of patients undergoing VBAC. Risks related to VBAC statistically are low, so guidance suggest that woman with one time history of CS with lower transverse incision is a candidate to be counseled and tried to do VBAC. The counseling process is related to a discussion of the risks associated with the VBAC trial, the risks associated with being carried out by $\mathrm{CS}$, and the estimated of success if VBAC action is taken. In a multicenter study report in the period 1999-2002 which was conducted by [17], involving 14,529 pregnant women with history of CS one time who started undergoing VBAC, data obtained in accordance with 10,690 pregnant women (73.6\%) were successful for deliver vaginally. This data showed that 3 out of 4 women with history of CS one time will success for VBAC. The factors that can influence and increase the success of VBAC are if the patient enters the spontaneous labor phase without prior induction, BMI $<30 \mathrm{~kg} / \mathrm{m} 2$, current pregnancy distance with previous $\mathrm{CS}>2$ years, previous CS indication is not due the reason of dystocia, gestational age $<$ 41 weeks, there was a previously successful history of vaginal delivery included successful VBAC, cervical dilatation $\geq$ $4 \mathrm{~cm}$ at admission, estimated fetal body weight $<4000 \mathrm{gr}$ [17]. Successful VBAC increases the confidence of the patient and the obstetric team. Conversely, an increasingly inactive lifestyle and poor tolerance for pain contribute to an increase in the number of CS.

Standardization of protocols, indications, regular and periodic evaluations of the CS indications in each hospital will help in limiting the level of CS. This will definitely help reduce maternal morbidity and mortality related to CS rates, reduce hospitalization after delivery and in turn improve the family economy. But on the contrary at the same time, one must immediately and with all efforts to carry out the process of laboring CS to women with strong clinical indications relating to the mother and baby, compared to delaying doing so in an effort to reduce the number of CS. Robson 
recommends that Groups 6,7,8,9 and 10 should not be targeted in an effort to reduce the level of CS operations. The relative risk is too high for a minimal reduction in numbers [11], [16], [18].

\section{CONCLUSION}

In conclusion, around 385 cases of labor with $\mathrm{CS}$ were obtained from a total of 1121 deliveries in 2018 (34.3\%). The highest rate was found in the age group of 25-29 years, mothers with first pregnancy (primigravida), most of the gestational age was term and the highest contribution of CS was Robson group 10.

\section{CONFLICT OF INTEREST}

Authors declare that they do not have any conflict of interest.

\section{REFERENCES}

[1] Kemenkes RI. Profil Kesehatan Indonesia. 2016.

[2] Mascarello KC, Horta BL, Silveira MF. Maternal complications and cesarean section without indication: systematic review and metaanalysis. Rev. saúde pública. 2017; 51: 105 (2017).

[3] Betrán AP, Ye J, Moller AB, Zhang J, Gülmezoglu AM, Torloni MR. The increasing trend in caesarean section rates: global, regional and national estimates: 1990-2014. PloS one 2016; 11(2): e0148343.

[4] Riskesdas R. Penyajian Pokok- Pokok Hasil Riset Kesehatan Dasar. 2013. (Indonesian).

[5] Villar J, Valladares E, Wojdyla D, Zavaleta N, Carroli G, Velazco A, et al. Caesarean delivery rates and pregnancy outcomes: the $2005 \mathrm{WHO}$ global survey on maternal and perinatal health in Latin America. The Lancet. 2006; 367(9525): 1819-1829.

[6] ACOG. Obstetric Care Consensus. Safe Prevention of The Primary Cesarean Delivery. Society for Maternal Fetal Medicine. 2019.

[7] World Health Organization. WHO: Robson Classification: Implementation Manual. [Internet] 2017 [cited 2020 Feb 9] Available from:

https://www.who.int/reproductivehealth/publications/maternal perina tal_health/robson-classification/en/

[8] Torloni MR, Betran AP, Souza JP, Widmer M, Allen T, Gulmezoglu $\mathrm{M}$, et al. Classifications for Cesarean Section: A Systematic Review. PLoS ONE 2011; 6(1): e14566.

[9] WHO. WHO Statement on Caesarean Section Rates. Jenewa. 2017.

[10] Vogel JP, Betrán AP, Vindevoghel N, Souza JP, Torloni MR, Zhang J, et al. WHO Multi-Country Survey on Maternal and Newborn Health Research Network. Use of the Robson classification to assess caesarean section trends in 21 countries: a secondary analysis of two WHO multicountry surveys. Lancet Glob Health. 2015; 3(5): e260-e270.

[11] Robson, M. Classification of caesarean sections. Fet. Matern. Med. Rev. 2001; 12: 23-39.

[12] Tanaka K, Mahomed K. The Ten-Group Robson Classification: A Single Centre Approach Identifying Strategies to Optimise Caesarean Section Rates. Obstetrics and Gynecology International. 2017: 1-5.

[13] Rydahl E, Declercq E, Juhl M, Maimburg RD. Cesarean section on a rise-Does advanced maternal age explain the increase? A population register-based study. PLOS ONE. 2019; 14: e0210655.

[14] Hanson C, Betrán AP, Opondo C, Mkumbo E, Manzi F, Mbaruku G, et al. Trends in caesarean section rates between 2007 and 2013 in obstetric risk groups inspired by the Robson classification: results from population-based surveys in a low-resource setting. BJOG: An International Journal of Obstetrics \& Gynaecology. 2019; 126(6): 690700 .

[15] Begum T, Rahman A, Nababan H, Hoque DME, Khan AF, Ali T, et al. Indications and determinants of caesarean section delivery: evidence from a population-based study in Matlab, Bangladesh. PloS One. 2017; 12(11): e0188074.

[16] Panicker S, Chitra TV. Analysis of caesarean delivery rates using the ten group classification system in a tertiary care hospital. Int J Reprod Contracept Obstet Gynecol. 2016: 3153-3157.
[17] Landon MB, Leindecker S, Spong CY, Hauth JC, Bloom S, Varner MW, et al. The MFMU Cesarean Registry: factors affecting the success of trial of labor after previous cesarean delivery. American journal of obstetrics and gynecology. 2005; 193(3): 1016-1023.

[18] Robson MS. Use of indications to identify appropriate caesarean section rates. The Lancet Global Health. 2018; 6: e820-e821. 